\title{
Review of Diesel Exhaust Aftertreatment Programs
}

Ronald L. Graves

Oak Ridge National Laboratory 
The appearance of this ISSN code at the bottom of this page indicates SAE's consent that copies of the paper may be made for personal or internal use of specific clients. This consent is given on the condition, however, that the copier pay a $\$ 7.00$ per article copy fee through the Copyright Clearance Center, Inc. Operations Center, 222 Rosewood Drive, Danvers, MA 01923 for copying beyond that permitted by Sections 107 or 108 of the U.S. Copyright Law. This consent does not extend to other kinds of copying such as copying for general distribution, for advertising or promotional purposes, for creating new collective works, or for resale.

SAE routinely stocks printed papers for a period of three years following date of publication. Direct your orders to SAE Customer Sales and Satisfaction Department.

Quantity reprint rates can be obtained from the Customer Sales and Satisfaction Department.

To request permission to reprint a technical paper or permission to use copyrighted SAE publications in other works, contact the SAE Publications Group.

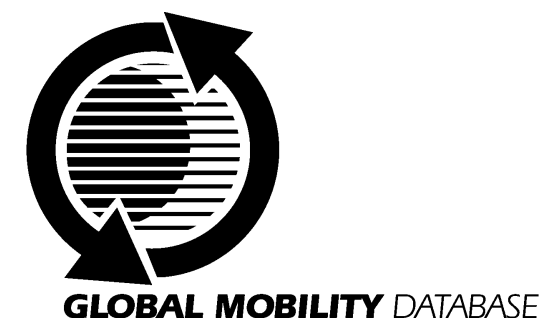

All SAE papers, standards, and selected books are abstracted and indexed in the Global Mobility Database

No part of this publication may be reproduced in any form, in an electronic retrieval system or otherwise, without the prior written permission of the publisher.

\section{ISSN 0148-7191}

Copyright 1999 Society of Automotive Engineers, Inc.

Positions and opinions advanced in this paper are those of the author(s) and not necessarily those of SAE. The author is solely responsible for the content of the paper. A process is available by which discussions will be printed with the paper if it is published in SAE Transactions. For permission to publish this paper in full or in part, contact the SAE Publications Group.

Persons wishing to submit papers to be considered for presentation or publication through SAE should send the manuscript or a 300 word abstract of a proposed manuscript to: Secretary, Engineering Meetings Board, SAE.

\section{Printed in USA}




\title{
Review of Diesel Exhaust Aftertreatment Programs
}

\author{
Ronald L. Graves \\ Oak Ridge National Laboratory
}

Copyright (c) 1999 Society of Automotive Engineers, Inc.

\begin{abstract}
The DOE Office of Heavy Vehicle Technologies (OHVT) and its predecessor organizations have maintained aggressive projects in diesel exhaust aftertreatment since 1993. The Energy Policy Act of 1992, Section 2027, specifically authorized DOE to help accelerate the ability of U. S. diesel engine manufacturers to meet emissions regulations while maintaining the compression ignition engines inherently high efficiency. A variety of concepts and devices have been evaluated for NOx and Particulate matter (PM) control. Additionally, supporting technology in diagnostics for catalysis, PM measurement, and catalyst/reductant systems are being developed. This paper provides a summary of technologies that have been investigated and provides recent results from ongoing DOE-sponsored R\&D. NOx control has been explored via active NOx catalysis, several plasmaassisted systems, electrochemical cells, and fuel additives. Both catalytic and non-catalytic filter technologies have been investigated for PM control.
\end{abstract}

\section{INTRODUCTION}

The Energy Policy Act of 1992, Section 2027, specifically authorized DOE to help accelerate the ability of U. S. diesel engine manufacturers to meet emissions regulations while maintaining the compression ignition engines inherently high efficiency. Shortly thereafter, the Department of Energy Heavy Duty Engine Technology Program initiated R\&D on diesel aftertreatment for NOx and PM to complement emission reduction efforts in combustion systems. Particularly from 1995-1999, Cummins Engine Company, Detroit Diesel Corporation, and Caterpillar, Inc., with several supplier organizations conducted extensive R\&D on NOx and PM aftertreatment. Several DOE laboratories have participated in supporting and enabling technology R\&D.

\section{EMISSION REQUIREMENTS}

The emission control requirements have evolved to be considerably more challenging than in 1995 when the DOE-funded aftertreatment efforts ramped up. Heavy duty diesels have an emissions target of $2.5 \mathrm{~g} / \mathrm{hp}-\mathrm{h}$ $\mathrm{NOx}+\mathrm{HC}$ for 2002, with PM at $0.10 \mathrm{~g} / \mathrm{hp}-\mathrm{h}(0.05 \mathrm{~g} / \mathrm{hp}-\mathrm{h}$ for urban bus). At this time, the heavy-duty diesel can likely meet this mark without aftertreatment, but probably with a notable penalty in fuel economy. Aftertreatment is still an option for heavy-duty diesels for regulations beyond 2004 or in a system strategy to maintain fuel efficiency.

The greatest challenge for diesel emissions compliance is in light duty vehicles, especially light trucks, given the expectations of mandated NOx levels of $0.05 \mathrm{~g} / \mathrm{mile}$. The challenge for the engine+aftertreatment system is depicted in Figure 1. Even at a relatively "clean" engineout emissions level, $1.0 \% \mathrm{NOx}$ index, the aftertreatment device may still have to be over $95 \%$ effective in a sport utility vehicle. When the DOE R\&D programs for heavy vehicle aftertreatment began in the mid-90s, the most ambitious NOx targets were around $0.20-0.50 \mathrm{~g} / \mathrm{mile}$ for light trucks. In that time frame, NOx removal of $70-90 \%$ had been thought to be an adequate goal.

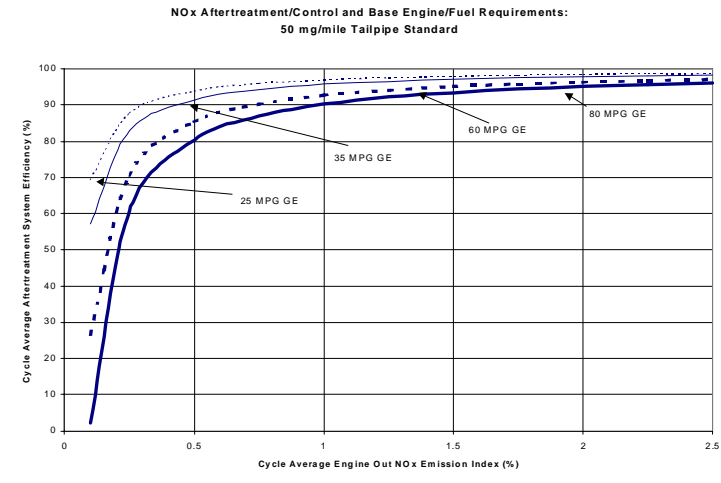

Figure 1a.

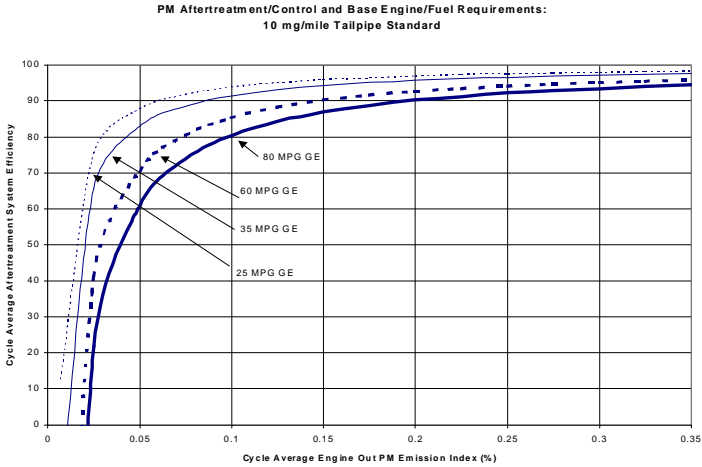

Figure 1b. 


\section{NOX CONTROL}

From 1995-98, the technology of focus in the DOEsponsored programs was the NOx catalyst, used with a reductant typically injected into the exhaust steam ahead of the catalyst. However, exploratory efforts on lowtemperature plasmas and plasma-assisted catalysis were conducted as well. Roughly 1500-2000 NOx catalyst formulations were screened during the period. Detroit Diesel Corporation was teamed with Allied Signal and Cummins Engine Company with Engelhard. Catalysts generally fell into two bins, "high-temperature" precious metal formulations, and "low-temperature" metal oxide formulations. The effects of space velocity, hydrocarbon reductant, and sulfur were examined for numerous formulations. Figure 2 illustrates some of the more promising results of the high-temperature catalysts in bench reactor tests. NOx conversion performance was highly dependent on the type of reductant. Though not shown here, the $\mathrm{HC} / \mathrm{NOx}$ ratio for best conversion was typically over six. Engine dynamometer stand tests generally showed a narrower temperature window of high conversion. Degradation of conversion up to 50 hours of use was minimal. For these catalysts to be very effective over a driving/test cycle, their low-temperature NOx conversion would obviously have to be improved, or else a novel thermal management scheme utilized.

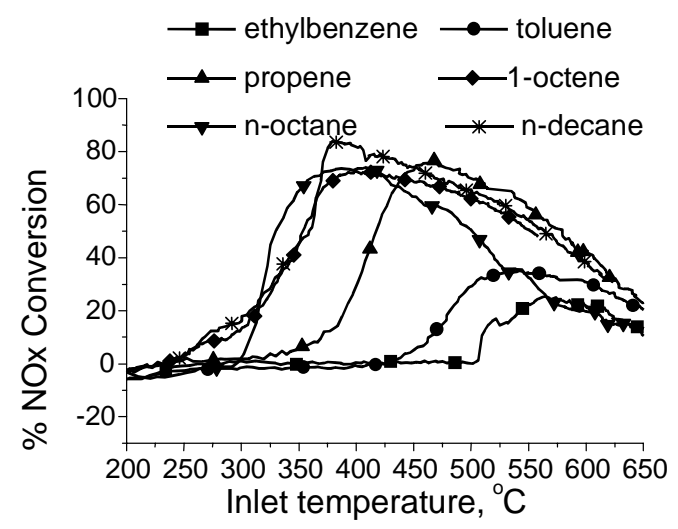

Figure 2. Bench test results from high-temperature catalyst (Allied-Signal data).

Cummins and Engelhard conducted similar studies on the effectiveness of various reductants, primarily with a low-temperature $\mathrm{Pt} \mathrm{NOx}$ catalyst. The ranking of effectiveness was found to be: C12-16 normal alkanes, olefins and C3 alcohols, diesel fuel (including some with about 1 ppm sulfur, aromatics, biodiesel fuel, branched aliphatics, short-chain (C3) normal alkanes. This team also noted that degradation of NOx conversion could be attributed to $\mathrm{SO} 2$ in the exhaust. During their R\&D program, Cummins/Engelhard examined NOx adsorption and sulfate-make characteristics of catalysts before funding for the effort was redirected in 1997.
Caterpillar led the evaluation of two bench-scale prototypes of low-temperature plasma devices since 1997. The devices, provided by two suppliers, were examined with simulated exhaust as well as a sidestream of real engine exhaust. Both suppliers received DOE funding to refine their systems and build prototypes for these tests. Representatives of other engine companies and auto manufacturers reviewed and guided the test plan. Site visits by ORNL staff and others were made to review the analytical equipment and procedures. The plasma device with no reductant and no designed catalyst was found to cause up to $30 \%$ of the feed NO to seemingly disappear, but subsequent analyses determined that NO was not being reduced to N2, converted to mostly other oxides of nitrogen. A plasma device that utilized monatomic $\mathrm{N}$ as a seed was found to have about $10 \%$ NO conversion, and in this case N2 was determined to be the product of conversion as desired.

A third non-catalytic plasma device was evaluated by DDC on a side-stream of engine exhaust. Over a comprehensive map of engine operation, NOx conversion was determined to be less than $10 \%$. Given the power requirements of the plasma system, singledigit conversion is inadequate. The plasma systems were thus generally proven to be primarily oxidation devices, with their best use perhaps as part of a plasma-assisted catalyst system or possibly for PM control.

\section{PM CONTROL}

Over the last few years the catalyzed soot filter (CSF) and continuously regenerated diesel particulate filter (CRDPF) have emerged as effective PM control technologies. Each has shortcomings; the CSF's regeneration temperature is higher than desired for lightduty applications, and the CRDPF is highly intolerant of SO2 in the exhaust. Cummins led a team to develop a non-catalytic filter that would be regenerated by an external energy source, a conventional microwave generator. The first generation configuration employed a filter paper media consisting of alumina fibers that were then coated with $\mathrm{SiC}$ via a chemical vapor deposition process. This provided a good coupling material, $\mathrm{SiC}$, for microwave energy, yet utilized a low-cost fiber not perceived as a health risk. The filter media is shown in Figure 3. Compared to monolithic filter media, the paper appeared to have less pressure drop at equivalent filtering efficiency. Since the microwave energy is transferred directly to the filter media, the rate of temperature rise was found to be much more rapid than electrical resistive heating (Figure 4). A series of bench and engine tests revealed that filtering efficiency was short of the goal of $85 \%$, and that structural integrity of the filter needed improvement. The CVD process was questioned for its ability to uniformly coat the filter media consistently. However the R\&D progress continues, and in a parallel effort by Industrial Ceramic Solutions, an alternate filter material has been identified (reference 1). 


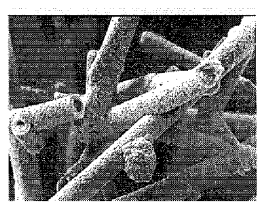

$3 k x-B S$

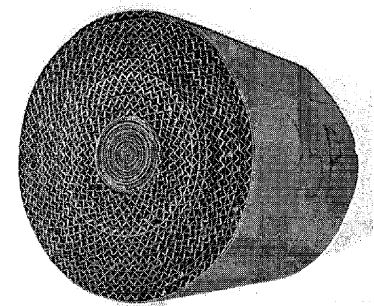

Figure 3. Filter media for microwave regeneration.

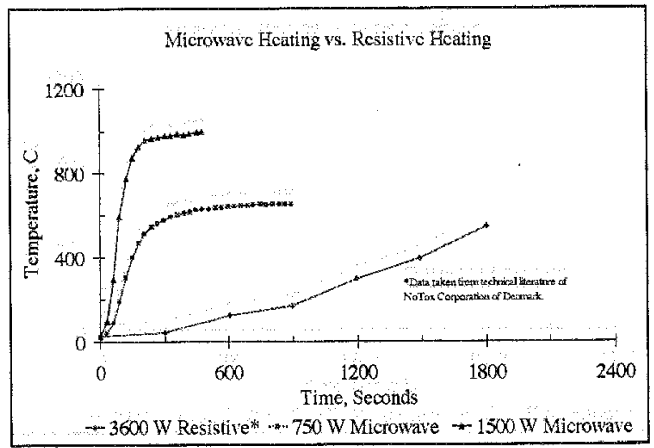

Figure 4. Heating rate with microwave energy vs. resistance energy.

\section{SUPPORTING TECHNOLOGY}

Researchers at Lawrence Berkeley National Laboratory are developing an instrument for measurement of nearreal-time particle mass and size distribution, the Diesel Particle Scatterometer (DPS). The underlying principle is the determination of light scattering and polarization. This will allow detection of diesel PM less than $10 \mathrm{~nm}$. Two prototype devices have been assembled, one of which will be delivered to Oak Ridge National Laboratory (ORNL), a collaborator in this program. The DPS is shown schematically in Fig 5. ORNL will compare the DPS to other devices such as the scanning mobility particle sizer (SMPS) and micro orifice uniform deposit (MOUDI), and finally utilize the device in emission control experiments. Further information on the DPS may be found in reference 2 .

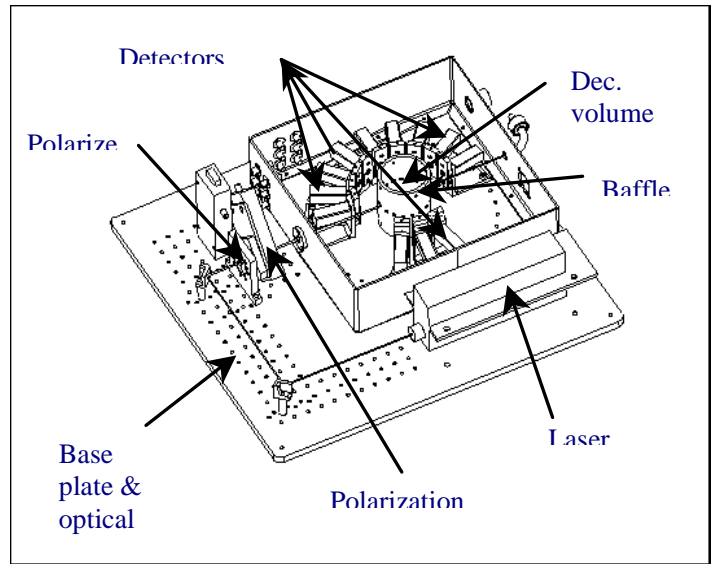

Figure 5. Diesel particle scatterometer.
In a CRADA with Cummins Engine Company, ORNL is developing and applying diagnostics to improve NOx control in aftertreatment systems. A key focus is elucidating fundamental kinetic barriers in realistic catalytic and gas-phase matrices. A secondary priority is better characterization and control of nitrogen species relevant to various aftertreatment strategies. We are using diffuse reflectance infrared Fourier transfer (DRIFT) and Raman spectroscopies for adsorbed species characterization and mass spectroscopy for high-speed, gas-phase NOx measurements. In DRIFT spectroscopy, the vibrational spectra of adsorbed species is directly probed by coupling an Fourier transform infrared (FTIR) excitation source (scanning over 400 to $5000-\mathrm{cm}^{-1}, 2$ to $25-\mu \mathrm{m}$ range) to collection optics biased to the diffusely scattered light. Raman spectroscopy indirectly accesses a species' energy-level structure via inelastic collision between a probe photon and the probed species; spectrally-shifted scattered light is indicative of the quantized energy levels of the probed species (W. Demtroder, Laser Spectroscopy basic concepts and instrumentation, Springer-Verlag, New York, NY, 1988) (reference 3). The Raman measurements may be configured to give enhance temporal response. ORNL is using these optical diagnostics to perform both broadspecies, temporally-averaged and narrow species, temporally-resolved surveys of relevant kinetic participants. With the mass-spectroscopy-based fastNOx instrument, we have demonstrated the capability to measure NOx storage and release cycles on commercial catalysts operating in the exhaust of running engines; this capability is beyond that of a standard chemiluminescence analyzer.

A CRADA between ORNL and Detroit Diesel Corporation has been underway since September 1997 with the purpose of determining how engine operation, $\mathrm{HC}$ reductant system design and fuels alter the formation of hydrocarbon species affecting the functionality of lean NOx catalysts. The work involves the speciation of exhaust HC's from a 19947.3 liter Navistar engine and a 1998 DDC Series 50 engine using in-cylinder post fuel injection and in-pipe (exhaust pipe) injection. A test matrix on the Navistar engine was completed in 1998 for different in-cylinder $\mathrm{HC}$ injection rates and injection crank angles. Regulated emissions, hydrocarbon speciation data and particulate matter were collected at two sample locations (turbo out and catalyst in) for in-pipe and incylinder $\mathrm{HC}$ injection and results were compared at different sample stations, injection crank angles, and $\mathrm{HC} /$ NOx ratios.

Although the regulated emissions data obtained at the two sample locations were similar, there was a significant change in the concentration of hydrocarbons generated (C11 to $\mathrm{C} 16)$ between in-pipe injection and in-cylinder injection as shown. Data shows that in-cylinder hydrocarbon injection provides a different level and mix of hydrocarbons. Species are not only affected by injection crank angle but by $\mathrm{HC} / \mathrm{NOx}$ ratios. A dramatic increase in total PM was noted as hydrocarbon injection rates 
increased, probably due to a larger fraction of soluble organics in the particulates, however increasing load decreased particulates. Exhaust temperature and engine load were not affected by secondary in-cylinder hydrocarbon injection at peak torque rpm, but there was a significant loss on power at the rated power rpm as load increased from $60 \%$ to $100 \%$ on the aftertreatment device.

The DDC Series 50 engine is now undergoing set up at the ORNL engine research facility for future hydrocarbon speciation work.

A Catalyzed Soot Filter (CSF) was obtained from a heavy-duty engine manufacturer and evaluated at ORNL to determine if the device actually creates ultrafine PM. A simulated bus cycle was used to load the filter for 150 hours, resulting in a five-fold increase in pressure drop across the CSF. A $75-90 \%$ reduction in PM weight was observed with the filter. All of the elemental carbon was removed and if water associated with $\mathrm{SO} 4$ is accounted for, more PM reduction would be seen. Filters are shown in Fig. 6 for visual impression.

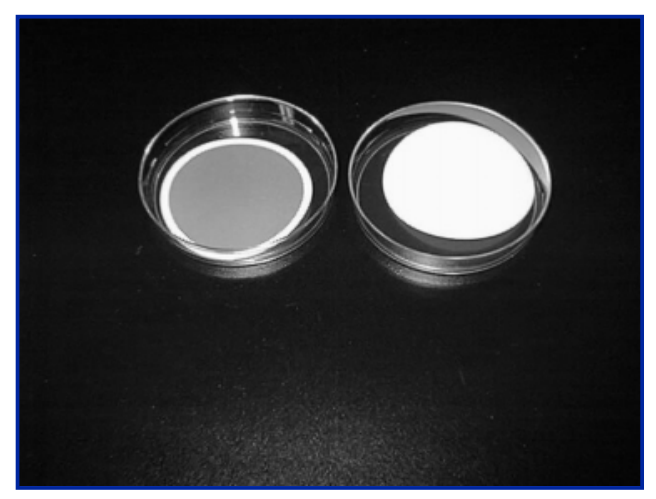

Figure 6. Sample filter from before the CSF and after. Sample time 10 minutes.

Test conditions: 1994 Navistar 7.3 liter turbo DI. 1900 rpm, 30\% load (exhaust temperature below the regeneration temperature).

Figure 7 shows what happens to the CSF-ut particle size as dilution increases. Note that the concentrations have been normalized to actual exhaust concentrations. At higher dilutions, it is harder for the nucleation particles to form (fewer collisions) and the particles approach the lower size limit of the instrument. We feel the majority of the PM collected is $\mathrm{SO} 4$ and water as the $\mathrm{SO} 4$ values were lower than normal. Figure 8 shows the effect of loading for long periods of time without regeneration. Note that the dilution effect shown in earlier slides disappears as the filter loads up.

In other words, there seems to be more nucleation with a loaded filter. One explanation: there might be more nucleation particles available to start off the nucleation process. The sample filters are still white even late in the game and the efficiency is still high.

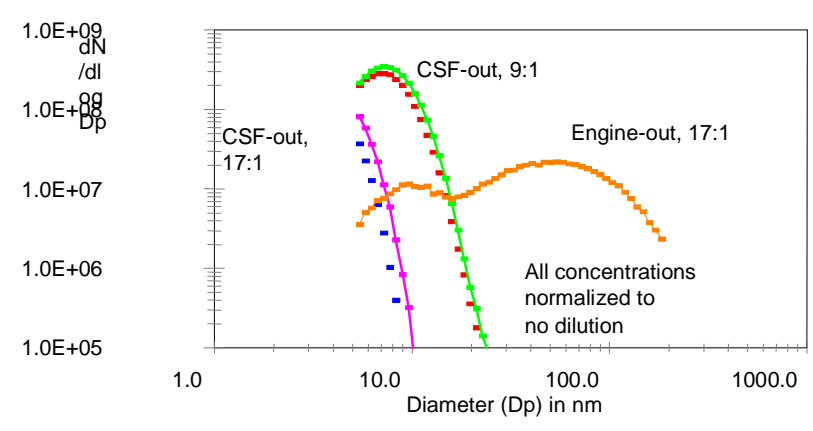

Figure 7. Engine-out vs. CSF-out particle size distribution.

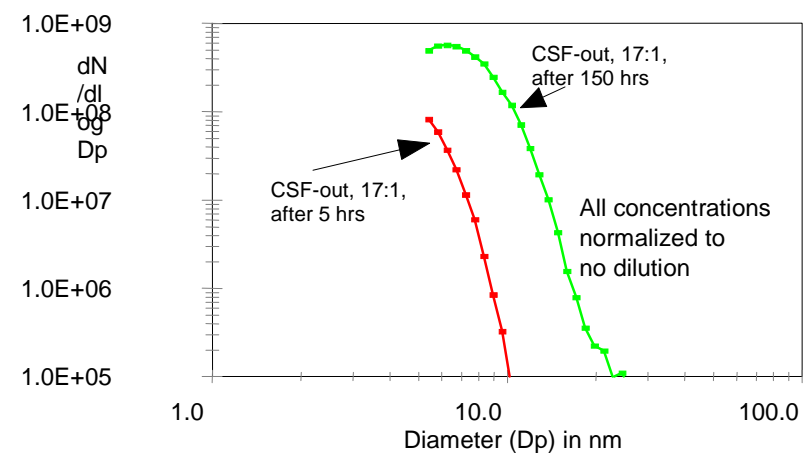

Figure 8. Effect of CSF loading on pm size distribution.

The TSI Scanning Mobility Particle Sizer was used for these measurements and duplicate and triplicate samples agreed well.

At present, most aftertreatment development efforts are conducted within the core engine R\&D programs in OHVT, except for enabling technology projects, which are performed by the national laboratories.

\section{ACKNOWLEDGEMENTS}

The authors sincere gratitude is conveyed to the following contributors to this review: Carl McDonald, Cummins, Kent Koshkarian, Arlon Hunt, Lawrence Berkeley National Lab, Nabil Hakim, Detroit Diesel Corporation, and from ORNL, Norberto Domingo, Bill Partridge, and John Storey.

\section{REFERENCES}

1. Nixdorf, Richard D., Final Report, ONRL/Sub/80XSZ896V, "Microwave Regenerated Particulate Filter Heating Performance," March1999.

2. Quinby-Hunt, M.S., et al., "Polarized Light Scattering by Aerosols in the Marine Atmospheric Boundary Layer," Applied Optics, 36, 5168-5184, 1997.

3. Demtroder, W., "Laser Spectroscopy Basic Concepts and Instrumentation," Springer Verlag, New York, NY, 1988. 